\title{
Oncogenic miR-100-5p is associated with cellular viability, migration and apoptosis in renal cell carcinoma
}

\author{
PEIJIE CHEN ${ }^{1-3^{*}}$, CANBIN LIN $^{1-3^{*}}$, JING QUAN $^{1,3}$, YULIN LAI $^{1,3}$, TAO HE $^{1}$, LIANG ZHOU ${ }^{1,3}$, XIANG PAN $^{1}$, \\ XUELING WU ${ }^{4}$, YONG WANG ${ }^{5}$, LIANGCHAO NI ${ }^{1}$, SHANGQI YANG ${ }^{1}$, TAO WANG ${ }^{6}$ and YONGQING LAI $^{1,3}$ \\ ${ }^{1}$ Department of Urology, Peking University Shenzhen Hospital, Shenzhen, Guangdong 518036; ${ }^{2}$ Department of \\ Urology, Shantou University Medical College, Shantou, Guangdong 515041; ${ }^{3}$ The Guangdong and Shenzhen \\ Key Laboratory of Male Reproductive Medicine and Genetics, Peking University Shenzhen Hospital, Institute \\ of Urology of Shenzhen PKU-HKUST Medical Center, Shenzhen, Guangdong 518036; ${ }^{4}$ Department of Urology, \\ Longgang District Central Hospital of Shenzhen, Shenzhen, Guangdong 518116; Departments of ${ }^{5}$ Reproduction \\ and ${ }^{6}$ Cardiovascular Surgery, Peking University Shenzhen Hospital, Shenzhen, Guangdong 518036, P.R. China
}

Received February 8, 2017; Accepted July 4, 2017

DOI: $10.3892 / \mathrm{mmr} .2017 .7139$

\begin{abstract}
As influencing factors of genesis and progression in several types of human tumor, microRNAs (miRs) serves roles in the regulation of tumor cell viability, migration, and apoptosis. The present research aimed to investigate the association between the function of miR-100-5p and renal cell carcinoma (RCC). miR-100-5p expression was determined in RCC tissue and paired normal tissue samples using reverse transcription-quantitative polymerase chain reaction. To assess the effects of miR-100-5p on cell viability, migration and apoptosis, multiple methods were used, including scratch wound assays, MTT assays, and flow cytometry. It was demonstrated that miR-100-5p was significantly upregulated in RCC tissue compared with in normal adjacent tissue samples. Furthermore, the viability and migration of 786-O and, ACHN cells tranfected with miR-100-5p was significantly increased compared with the negative control group. In addition, miR-100-5p-transfected 786-O and ACHN cells demonstrated significantly reduced cellular apoptotic rates compared with the negative control group. To the best of our knowledge, the present study is the first to report an association between
\end{abstract}

Correspondence to: Professor Yongqing Lai, Department of Urology, Peking University Shenzhen Hospital, 1120 Lianhua Road, Shenzhen, Guangdong 518036, P.R. China

E-mail: yqlord@163.com

Professor Tao Wang, Department of Cardiovascular Surgery, Peking University Shenzhen Hospital, 1120 Lianhua Road, Shenzhen, Guangdong 518036, P.R. China

E-mail: szwangtao@126.com

*Contributed equally

Key words: microRNA, miR-100-5p, renal cell carcinoma, oncogene
miR-100-5p and RCC. The results of the current study suggest that tumor oncogene miR-100-5p could be used as a diagnostic biomarker for RCC.

\section{Introduction}

As the seventh most prevalent cancer type in men and the tenth most prevalent cancer type in women, renal cancer accounts for 5 and $3 \%$ of all malignant tumors in men and women (1). Renal cancer is the fourteenth most common cancer with increasing incidence and mortality rates in developing countries $(2,3)$. Renal cell carcinoma (RCC) is the major subtype of renal cancers, accounting for approximately $90 \%$ of total renal cancers $(4,5)$. There are three most common histological subtypes of RCC, including clear cell RCC (70\%), papillary RCC (10\%) and chromophobe RCC (5\%) (5). In addition, the men to women ratio of RCC is over 2:1 (6). Nowadays, the aetiology of RCC cannot be explored clearly, but hypertension, obesity, smoking and another risk factors are associated with RCC (7). In Canada, 5900 people was diagnosed as RCC in 2012 and over 65150 new cases of RCC in USA in $2013(6,8)$. Lacking early-warning signs and protean clinical manifestations are the characters of RCC (9). Therefore, $25 \%$ of RCC had been advanced when it was initially diagnosed. Unfortunately, after resection of localized disease, recurrence and metastasis still appear in $33.3 \%$ of patients with $\operatorname{RCC}(10,11)$. What's more, chemotherapy or radiotherapy are inefficient dealing with RCC (12). Thus, it is significant to identify a novel molecular biomarker for early detection of RCC.

MicroRNAs (microRs, miRs) are small non-coding RNAs with 20 23 nucleotides in length and cleaved from pre-miRNA with hairpin-shaped (13). Previous studies have reported that miRNAs play a momentous role in numerous cell processes by binding the 3'-untranslated regions of messenger RNA (13-16). miRNAs exert an effect on cell growth, proliferation, apoptosis, differentiation, migration and metabolism (17). Increasing evidence demonstrates that dysregulated phenomena of miRNAs expression exist 
in different types of tumor and upregulated miRNAs act as tumor factors while downregulated miRNAs act as tumor suppressors (18-20). In addition, one miRNA could regulate several mRNAs and several miRNAs also could regulate one mRNA (19). However, the specific roles of certain miRNAs in cancer have remained to be further discussed. Therefore, as a biomarker for RCC, miRNA has potential value in diagnosis, prognosis even novel treatment.

As a kind of miRNAs, miR-100-5p has been demonstrated to be abnormally expressed in a variety of different tumors, including esophageal squamous cancer (21), glioblastoma (22), breast cancer (23) and gastric cancer (24). However, to the best of our knowledge, the function of miR-100 has remained elusive in RCC. Thus, the present study aimed to detect the expression of miR-100-5p in RCC and normal tissues and to explore the effects of miR-100-5p through RCC cell viability, migration and apoptosis.

\section{Materials and methods}

Sample collection. There are altogether 22 paired RCC tissues and adjacent normal renal tissues (ANTs), which were gained from Peking University Shenzhen Hospital (Shenzhen, Guangdong, China). ANTs were gained at the normal region over $2 \mathrm{~cm}$ distance from visible tumor range. Upon written consent of the patients from Peking University Shenzhen Hospital between January 2015 and January 2016, the present research was ratified by the ethics committee of Peking University Shenzhen Hospital. After being examined and classified through hematoxylin and eosin staining, the collected tissues were dipped in RNAlater (Qiagen $\mathrm{GmbH}$, Inc., Hilden, Germany) about $30 \mathrm{~min}$ and were stored at $-80^{\circ} \mathrm{C}$ refrigerator. The clinical and pathological information of the patients with RCC is summarized in Table I.

RNA extraction, cDNA synthesis and quantitative polymerase chain reaction $(q P C R)$. TRIzol Reagent (Invitrogen; Thermo Fisher Scientific, Inc., Waltham, MA, USA) was used for extracting total RNA of RCC tissues and normal adjacent tissues. Then RNeasy Maxi kit (Qiagen $\mathrm{GmbH}$ ) was used for purified purifying total RNA. The concentration of RNA was detected by NanoDrop 2000/2000c (Thermo Fisher Scientific, Inc.), and the RNA samples with optical density ratio (260/280) of 1.8-2.0 were stored for subsequent experiments. Each RNA sample of $1 \mu \mathrm{g}$ was reversely transcribed to cDNA with the miScript Reverse Transcription kit (Qiagen $\mathrm{GmbH}$ ), and the temperature for the reverse transcription reaction was $37^{\circ} \mathrm{C}$ for $60 \mathrm{~min}, 95^{\circ} \mathrm{C}$ for $5 \mathrm{~min}$ and storage at $4^{\circ} \mathrm{C}$. To quantify the expression levels of miR-100-5p, quantitative polymerase chain reaction (qPCR) analysis was performed using cDNA by the miScript SYBR ${ }^{\circledR}$ Green PCR kit (Qiagen $\mathrm{GmbH}$ ) on a Roche Lightcycler 480 Real-Time PCR System. The following primers (Invitrogen) were used: forward primer of miR-100-5p, and the reverse primer was provided by the miScript SYBR ${ }^{\circledR}$ Green PCR kit (Qiagen $\mathrm{GmbH}$ ); forward primer of Internal control of U6 and reverse. Thermocycling conditions of PCR were showed below: $95^{\circ} \mathrm{C}$ for $1 \mathrm{~min}$, then 40 cycles of $95^{\circ} \mathrm{C}$ for $15 \mathrm{sec}, 55^{\circ} \mathrm{C}$ for $30 \mathrm{sec}$ and $72^{\circ} \mathrm{C}$ for $30 \mathrm{sec}$. All steps above followed the manufacturer's instructions. The expression of miR-100-5p was calculated by the $2^{-\Delta \Delta C q}$ method (25).
Table I. Clinicopathological features of patients with renal cell carcinoma.

\begin{tabular}{lc}
\hline Characteristic & Number of patients \\
\hline Mean age, range (years) & $48(24-63)$ \\
Males & 8 \\
Females & 14 \\
Histological type & \\
Clear cell & 20 \\
Papillary & 2 \\
pT-stage & \\
T1 & 14 \\
T2 & 6 \\
T3 + T4 & 2 \\
Fuhrmann grade & \\
I & 5 \\
II & 15 \\
III & 1 \\
IV & 1 \\
AJCC clinical stage & \\
I & 6 \\
II & 14 \\
III + IV & 2 \\
\hline
\end{tabular}

pT, primary tumor; AJCC, American joint committee on cancer.

Cell culture and transfection. Dulbecco's Modified Eagle's Medium (DMEM basic; Gibco; Thermo Fisher Scientific, Inc.) with $10 \%$ Fetal Bovine Serum (FBS; Gibco), 1\% Penicillin Streptomycin (Pen Strep; Gibco) and 1\% Glutamine (Gibco) were used for cell culture of the 786-O cell and ACHN cell lines of human RCC (American Type Culture Collection, Manassas, VA, USA) in a $37^{\circ} \mathrm{C}$ humidified incubator comprising $5 \% \mathrm{CO}^{2}$. To improve the level of miR-100-5p, cells at a confluence of $60-70 \%$ were transfected with chemically synthesized miR-100-5p mimics (GenePharma, Inc., Shanghai, China) or negative control (NC) miRNA using Lipofectamine 2000 (Invitrogen) in Opti-MEM ${ }^{\circledR}$ I Reduced Serum Medium (Gibco). To assess the transfection efficiency and miR-100-5p expression, fluorescence microscopy (using a DMIRB fluorescence microscope; Leica Microsystems, Wetzlar, Germany) and reverse transcription quantitative polymerase chain reaction (RT-qPCR) were performed after the transfection. The sequences of the miRNAs and primers are showed in Table II.

Cell Counting Kit-8 (CCK-8) assay. To estimate the viability of 786-O cell and ACHN cells in vitro, CCK-8 assay was done as a useful performance. Each well of a 96-well plate was seeded into about $5 \times 10^{3}$ cells, which were transfected with 5 pmol of miR-100-5p mimics, inhibitors, NC or inhibitor NC $24 \mathrm{~h}$ later. At 0, 24, 48 and $72 \mathrm{~h}$ after incubation, $10 \mu \mathrm{l} \mathrm{CCK}-8$ (Beyotime Institute of Biotechnology, Haimen, China) was put in each well, which has been incubated for 0.5 hat $37^{\circ} \mathrm{C}$ in a humidified incubator comprising $5 \% \mathrm{CO}^{2}$. Finally, an ELISA 
Table II. Sequences of primers and microRNAs.

\begin{tabular}{ll}
\hline Primer/microRNA & \\
\hline miR-100-5p & Sequence \\
U6 & $\begin{array}{l}\text { Forward 5'-AACCCGTAGATCCGAACTTGTG-3' } \\
\text { Reverse provided by the miScript SYBR }{ }^{\circledR} \text { Green }\end{array}$ \\
miR-100-5p mimics & Forward 5'-CTCGCTTCGGCAGCACA-3' \\
NC & Reverse 5'-ACGCTTCACGAATTTGCGT-3' \\
& Forward 5'-AACCCGUAGAUCCGAACUUGUG-3' \\
miR-100-5p inhibitor & Reverse 5'-CAAGUUCGGAUCUACGGGUUUU-3' \\
NC inhibitor & Forward 5'-UUCUCCGAACGUGUCACGUTT-3' \\
& Reverse 5'-ACGUGACACGUUCGGAGAATT-3' \\
& 5'-CACAAGUUCGGAUCUACGGGUU-3' \\
& 5'-CAGUACUUUUGUGUAGUACAA-3'
\end{tabular}

miR, microRNA; NC, negative control.

microplate reader (model 680; Bio-Rad Laboratories, Inc., Hercules, CA, USA) was used to detect the optical density $(490 \mathrm{~nm})$ of 96-well plate.

3-(4,5-dimethylthiazol-2-yl)-2,5-diphenyltetrazolium bromide (MTT) assay. To estimate the viability of 786-O cell and ACHN cells in vitro, MTT assay was done as a useful performance. Each well of a 96 -well plate was seeded into about $5 \times 10^{3}$ cells, which were transfected with 5 pmol of miR-100-5p mimics or negative control using Lipofectamine ${ }^{\circledR} 200024$ h later. 4 days later, $20 \mu \mathrm{l} \mathrm{MTT} \mathrm{(5} \mathrm{mg/ml;} \mathrm{Sigma-Aldrich,} \mathrm{St} \mathrm{Louis,} \mathrm{MO,}$ USA) was put in each well. Then continued to incubate for $4 \mathrm{~h}$ at $37^{\circ} \mathrm{C}$ in a humidified incubator comprising $5 \% \mathrm{CO}^{2}$. After removing the medium with $\mathrm{MTT}, 100 \mu \mathrm{l}$ dimethylsulfoxide (Sigma-Aldrich Trading Co., Ltd., Shanghai, China) was put in each well, which was then shaken by reciprocating decolorization shaking table (TSB-108, Qilinbeier, Jiangsu, China) for $10 \mathrm{~min}$ in a dark condition. Finally, an ELISA microplate reader (model 680; Bio-Rad Laboratories, Inc., Hercules, CA, USA) was used to detect the optical density $(595 \mathrm{~nm})$ of 96-well plate.

Wound healing assay. To estimate the migratory aptitude of 786-O cell and ACHN cells in vitro, wound healing assay was done as a useful performance. Each well of a 12-well plate was seeded into about $3 \times 10^{5}$ cells, which were transfected with 100 pmol of miR-100-5p mimics or negative control using Lipofectamine ${ }^{\circledR} 200024 \mathrm{~h}$ later. At $6 \mathrm{~h}$ after transfection, monolayer of cells was scratched to generate a straight line by a steril tip of $200 \mu \mathrm{l}$ pipette. Floating cells were cleared away with Phosphate Buffered Saline (PBS; Gibco; Thermo Fisher Scientific, Inc.) and were cultured continually. The images of the straight line at 0 and $12 \mathrm{~h}$ after rinsing were from Leica DMIRB Inverted Fluorescence Microscope (Leica Microsystems GmbH, Wetzlar, Germany) with a digital camera system (Olympus Corporation, Tokyo, Japan). The assays were established in triplicate and were repeated for three times.

Transwell assay. To estimate the invasive and migratory aptitude of 786-O cell and ACHN cells in vitro, Transwell assay was done as a useful performance. According to the manufacturer's protocol, transwell chamber inserts (BD Biosciences, Franklin Lakes, NJ, USA) with Matrigel were used for invasion and Transwell chamber inserts without Matrigel were used for migration. At $24 \mathrm{~h}$ after transfection, a density of $1 \times 10^{4}$ cells were plated into the upper chamber of the insert with $200 \mu \mathrm{l}$ serum-free DMEM when the bottom of the insert was filled by $500 \mu \mathrm{l}$ DMEM with $10 \%$ FBS. The 786-O cells were cultured $36 \mathrm{~h}$ for migration and $48 \mathrm{~h}$ for invasion. The ACHN cells were cultured $36 \mathrm{~h}$ for migration and $60 \mathrm{~h}$ for invasion. The migrated or invaded cells on the bottom of the inserts were stained with crystal violet and counted with a microscope.

Flow cytometric assay. To estimate the apoptotic rates of 786-O cell and ACHN cells in vitro, flow cytometry assay was done as a useful performance. Each well of a 6-well plate was seeded into about $3 \times 10^{5}$ cells, which were transfected with 200 pmol of miR-100-5p mimics or negative control using Lipofectamine ${ }^{\circledR} 200024 \mathrm{~h}$ later. At $48 \mathrm{~h}$ after transfection, the harvested cells with being washed by cold PBS twice were re-suspended in $100 \mu 11 \mathrm{X}$ binding buffer. Subsequently $5 \mu \mathrm{l}$ propidium iodide (PI; Invitrogen) and $5 \mu \mathrm{l}$ Annexin V-fluorescein isothiocyanate (Invitrogen) were put into each cellular suspension. 6-well plate was incubated at room temperature for $15 \mathrm{~min}$ in darkness. Finally, each cellular suspension was added with $400 \mu \mathrm{l}$ binding buffer again and was assessed the apoptotic rat by flow cytometry (EPICS Xl-4, Beckman Coulter, Brea, CA, USA).

Statistical analysis. Paired t-test was applied to analyze expression levels of miR-100-5p paired RCC tissues and ANTs. The assays were analyzed through Student's t-test for characterizing phenotypes of cells. All data were analyzed using the SPSS 19.0 statistical software package (IBM SPSS, Armonk, $\mathrm{NY}$, USA). $\mathrm{P}<0.05$ was considered to indicate a statistically significant difference.

\section{Results}

miR-100-5p was upregulated in RCC tissues and cell lines. qPCR was performed in 22 paired RCC tissues and ANTs 


\section{A}

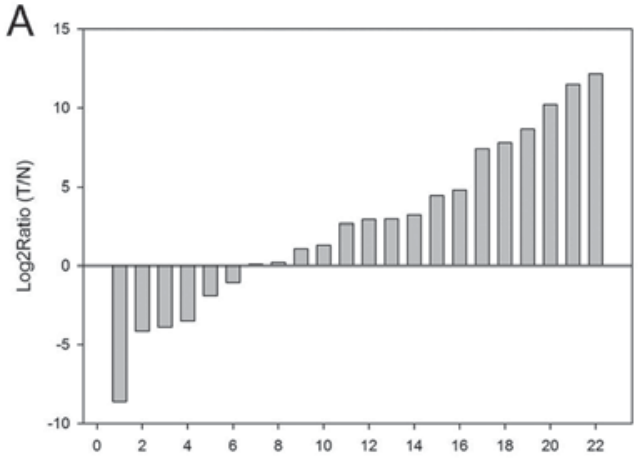

c



B

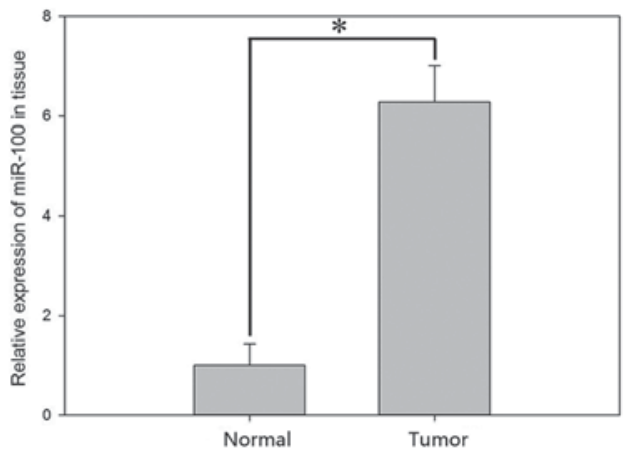

D

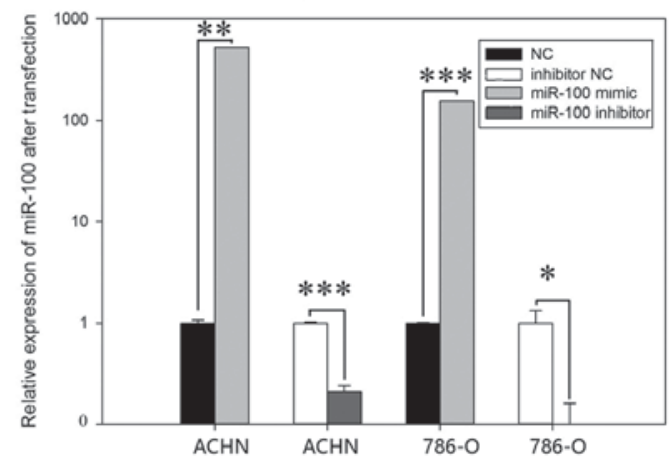

Figure 1. Expression levels of miR-100-5p in 22 paired tissue samples and cell lines. (A) Log 2 ratios of miR-100-5p expression in 22 paired $\mathrm{T}$ and $\mathrm{N}$ tissues. (B) The relative expression of miR-100-5p in tumor and normal tissues. (C) The relative expression of miR-100-5p in RCC cell lines. (D) The expression of miR-100-5p after transfection in ACHN and 786-O cells. ${ }^{*} \mathrm{P}<0.05,{ }^{* *} \mathrm{P}<0.01,{ }^{* * *} \mathrm{P}<0.001$. miR, microRNA; T, RCC tissues; $\mathrm{N}$, normal kidney tissues; NC, negative control.

for determining the expression level of miR-100-5p. Fig. 1A presented relative expression of miR-100-5p [Log2 (T/N)]. As shown in Fig. 1B, the expression of miR-100-5p in RCC tissues was significantly higher than those in the paired normal tissues $(\mathrm{P}<0.05)$. Expression levels of miR-15a-5p in HEK-293T normal human embryo kidney cell line the two RCC cell lines were also quantified and Fig. $1 \mathrm{C}$ indicated that expression of miR-100-5p was significantly higher in 786-O $(\mathrm{P}<0.01)$ and ACHN $(\mathrm{P}<0.05)$ compared with $293 \mathrm{~T}$ cells, which was in accordance with the expression pattern of miR-100-5p in RCC tissues.

Validation of cell transfection efficiency. RT-qPCR was performed for determining whether the expression level of miR-100-5p was changed by transfecting miR-100-5p mimic or inhibitor. As shown in Fig. 1D, the expression levels of miR-100-5p were downregulated by $79.02 \%$ in $\mathrm{ACHN}$ $(\mathrm{P}<0.001)$ and $93.96 \%$ in $786-\mathrm{O}(\mathrm{P}<0.01)$ following transfection with miR-100-5p inhibitor compared with the inhibitor NC. The expression levels of miR-100-5p were 523.96 times higher $(\mathrm{ACHN}$ cells, $\mathrm{P}<0.05)$ and 153.98 times higher $(786-\mathrm{O}$ cells, $\mathrm{P}<0.001)$ in cells following transfection with miR-100-5p mimics compared with NC.

miR-100-5p mimics promoted RCC cell viability and miR-100-5p inhibitor inhibited RCC cell viability. The effect of miR-100-5p on RCC cell viability was determined by CCK-8 assay in vitro. Compared with the NC control group, upregulation of miR-100-5p promoted cell viability when downregulation of miR-100-5p inhibited cell viability. The cell viability of ACHN cells was increased by $29.36 \%$ $(\mathrm{P}<0.05), 27.38 \%(\mathrm{P}<0.05)$ and $41.77 \%(\mathrm{P}<0.05$; Fig. $2 \mathrm{~A})$ and that of 786-O cells was increased by $8.12 \%(\mathrm{P}<0.05), 21.70 \%$ $(\mathrm{P}<0.05)$ and $11.38 \%(\mathrm{P}<0.01$; Fig. $2 \mathrm{~B})$ at 24,48 and $72 \mathrm{~h}$ after transfection with miR-100-5p mimics, respectively. The results demonstrated that the cell viability of ACHN cells was decreased by $6.75 \%, 12.67 \%(\mathrm{P}<0.05)$ and $24 \%(\mathrm{P}<0.01$; Fig. 2C) and that of 786-O cells was decreased by $13.20 \%$ $(\mathrm{P}<0.05), 27.98 \%(\mathrm{P}<0.05)$ and $26.44 \%(\mathrm{P}<0.01$; Fig. $2 \mathrm{D})$ at 24, 48 and $72 \mathrm{~h}$ after transfection with miR-100-5p inhibitor, respectively. To validate the viability of miR-100-5p on RCC cell, a MTT assay also was performed. The results demonstrated that upregulation of miR-100-5p promoted cell viability when downregulation of miR-100-5p inhibited cell viability. As shown in Fig. 3, upregulation of miR-100-5p significantly increased the cell viability of ACHN cells by $36.34 \%(\mathrm{P}<0.001)$ and $786-\mathrm{O}$ cells by $53.77 \%(\mathrm{P}<0.01)$. Downregulation of miR-100-5p significantly decreased the cell viability of ACHN cells by $20.97 \%(\mathrm{P}<0.05)$ and $786-\mathrm{O}$ cells by $30.02 \%$ $(\mathrm{P}<0.05)$. The results revealed that miR-100-5p may promote cell viability of RCC.

miR-100-5p mimics promoted RCC cell mobility and miR-100-5p inhibitor inhibited RCC cell mobility. Wound healing assay and transwell assay were performed for investigating the effect of miR-100-5p on cell mobility in 786-O and ACHN RCC cell lines. As showed in Fig. 4, the results of wound healing assay of ACHN showed that the migratory distance of 

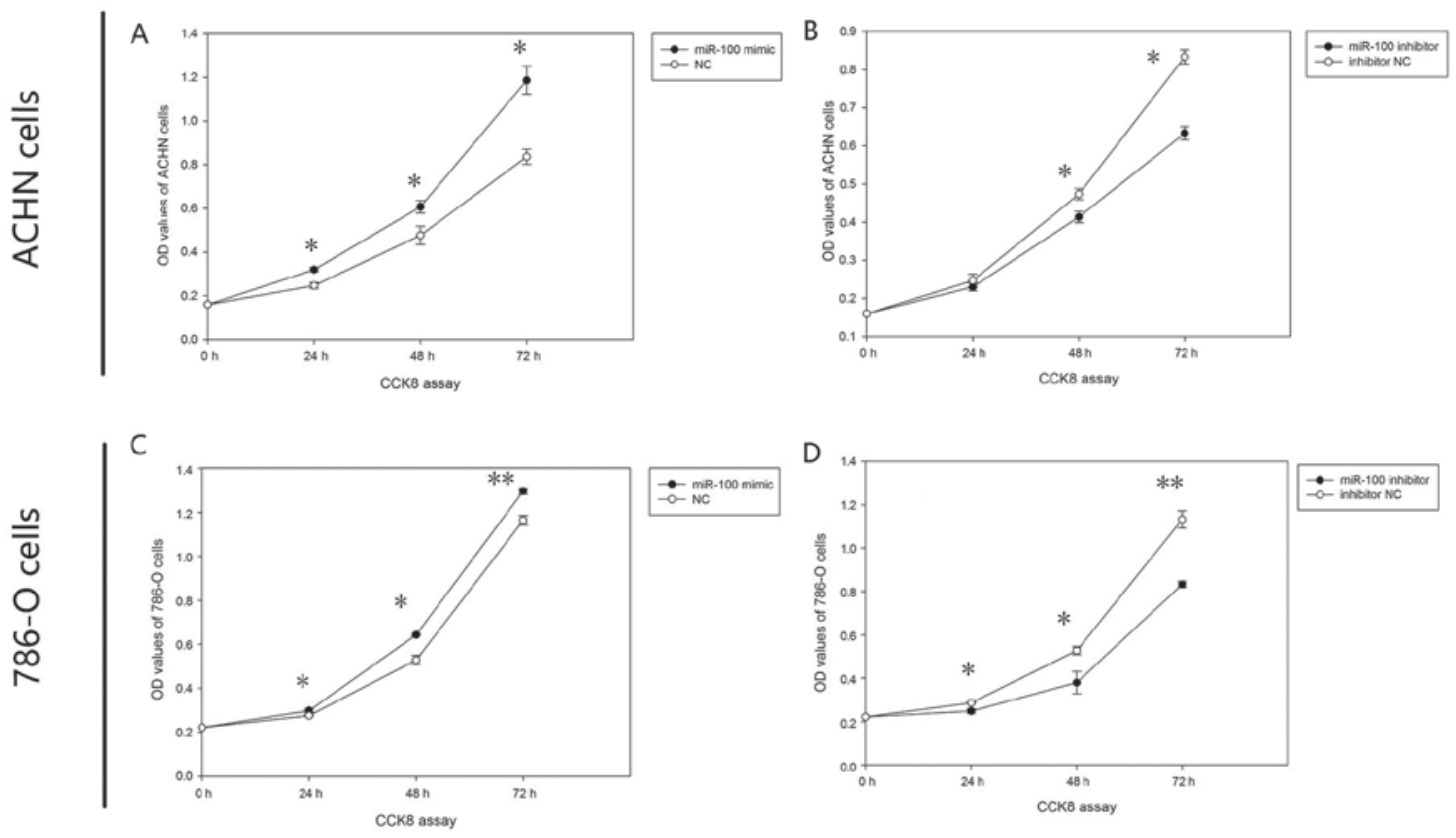

Figure 2. CCK-8 assay was used to assess the cell viability. (A) ACHN cells transfected with miR-100-5p mimic or NC and (B) miR-100-5p inhibitor or inhibitor NC. (C) 786-O cells transfected with miR-100-5p mimic or NC and (D) miR-100-5p inhibitor or inhibitor $\mathrm{NC}$. ${ }^{*} \mathrm{P}<0.05,{ }^{* *} \mathrm{P}<0.01,{ }^{* * *} \mathrm{P}<0.001 . \mathrm{NC}$, negative control; OD, optical density; CCK-8, Cell Counting Kit 8.

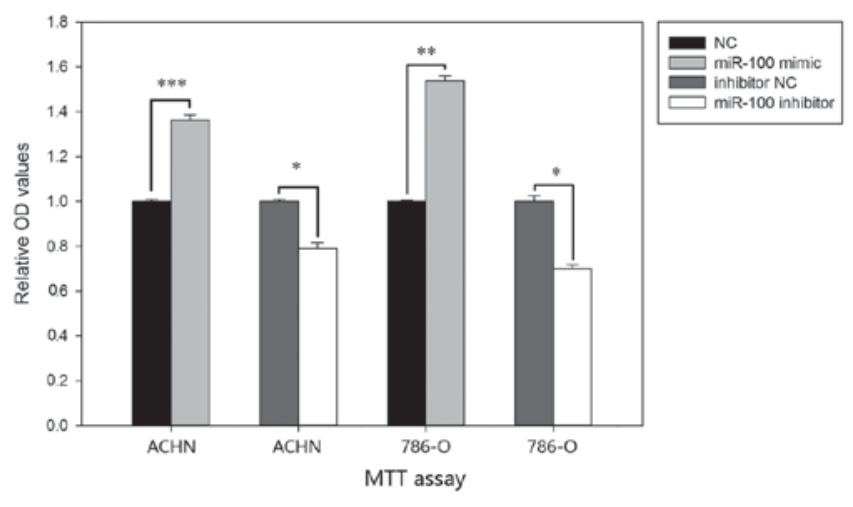

Figure 3. MTT assay of ACHN and 786-O cells. ${ }^{*} \mathrm{P}<0.05,{ }^{* *} \mathrm{P}<0.01,{ }^{* * *} \mathrm{P}<0.001$. miR, microRNA; NC, negative control.

cells transfected with miR-100-5p mimics was significantly promoted by $89.13 \%(\mathrm{P}<0.001)$ at $12 \mathrm{~h}$ compared with cells transfected with NC (Fig. 4C). By contrast, downregulation of miR-100-5p by transfecting miR-15a-5p inhibitors reduced migratory distances by $37.00 \%(\mathrm{P}<0.01)$ in $\mathrm{ACHN}$ at $12 \mathrm{~h}$ compared cells transfected with inhibitor NC (Fig. 4C). As showed in Fig. 4, the results of wound healing assay of 786-O showed that the migratory distance of cells transfected with miR-100-5p mimics was significantly promoted by $26.85 \%$ $(\mathrm{P}<0.001)$ at $12 \mathrm{~h}$ compared with cells transfected with $\mathrm{NC}$ (Fig. 4B). By contrast, downregulation of miR-100-5p by transfecting miR-15a-5p inhibitors reduced migratory distances by $53.07 \%(\mathrm{P}<0.001)$ in $786-\mathrm{O}$ at $12 \mathrm{~h}$ compared cells transfected with inhibitor NC (Fig. 4B).

Transwell assay (Fig. 5B) demonstrated that the migratory ability of 786-O cells transfected with miR-100-5p mimics was increased by $68.49 \%(\mathrm{P}<0.01)$ and in miR-100-5p inhibitor group was reduced by $57.35 \%(\mathrm{P}<0.001)$. In 786-O cells, invasive ability was reduced by $57.37 \%(\mathrm{P}<0.05)$ in $\mathrm{miR}-100-5 \mathrm{p}$ inhibitor group and increased by $100.75 \%(\mathrm{P}<0.01)$ in miR-100-5p mimic group (Fig. 5C).

The results of the Transwell assay in ACHN were presented in Fig. 5. The migratory ability of ACHN cells transfected with miR-100-5p mimics was increased by $255.98 \%(\mathrm{P}<0.001)$ and in miR-100-5p inhibitor group was reduced by $71.20 \%$ $(\mathrm{P}<0.05)$ (Fig. 5D). Invasive ability was reduced by $54.73 \%$ $(\mathrm{P}<0.01)$ in miR-100-5p inhibitor group and increased by $97.83 \%(\mathrm{P}<0.05)$ in miR-100-5p mimic group (Fig. 5E). The results indicated that miR-100-5p promoted the mobility of RCC cell.

miR-100-5p mimics inhibited RCC cell apoptosis and miR-100-5p inhibitor induced cell apoptosis. Flow cytometric analysis was used to determine the apoptotic rate of miR-100-5p on the of RCC cells at $48 \mathrm{~h}$ after transfection. The results showed that the early apoptotic rate of ACHN cells transfected with miR-100-5p mimics or NC was $8.38 \pm 0.49$ vs. $15.16 \pm 0.88 \%(\mathrm{P}<0.01$; Fig. $6 \mathrm{C})$ and the apoptotic rate of ACHN cells with miR-100-5p inhibitors or inhibitor NC was $25.33 \pm 1.26$ vs. $16.13 \pm 1.08 \%$ ( $\mathrm{P}<0.05$; Fig. $6 \mathrm{C})$. As presented in Fig. 6B, the early apoptotic rate of 786-O cells transfected with miR-100-5p mimics or NC was $5.23 \pm 1.42$ vs. $15.16 \pm 1.53 \%$ $(\mathrm{P}<0.05)$ and the apoptotic rate of 786-O cells with miR-100-5p inhibitors or inhibitor NC was $33.45 \pm 1.42$ vs. $17.00 \pm 2.45 \%$ $(\mathrm{P}<0.01$; Fig. 6B). The results showed that downregulation of miR-100-5p induced cell apoptosis in RCC.

\section{Discussion}

Dysfunction of tumor suppressor genes and activation of cancer-promoting gene play an important role in tumorigenesis. 
A

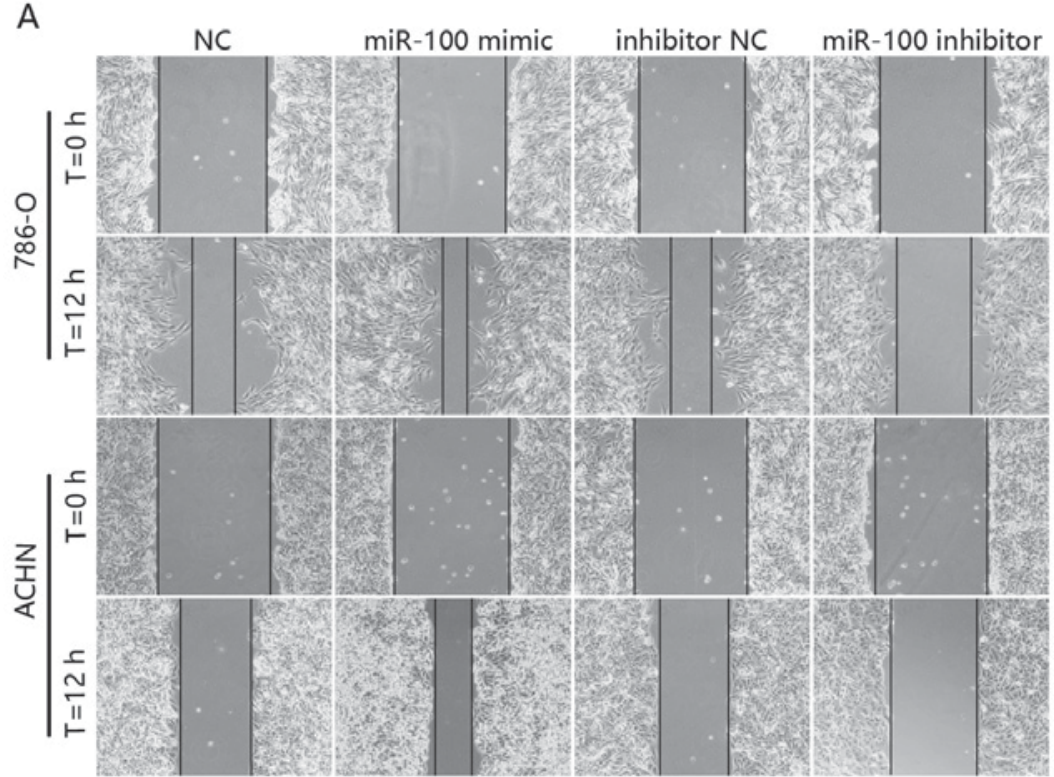

B

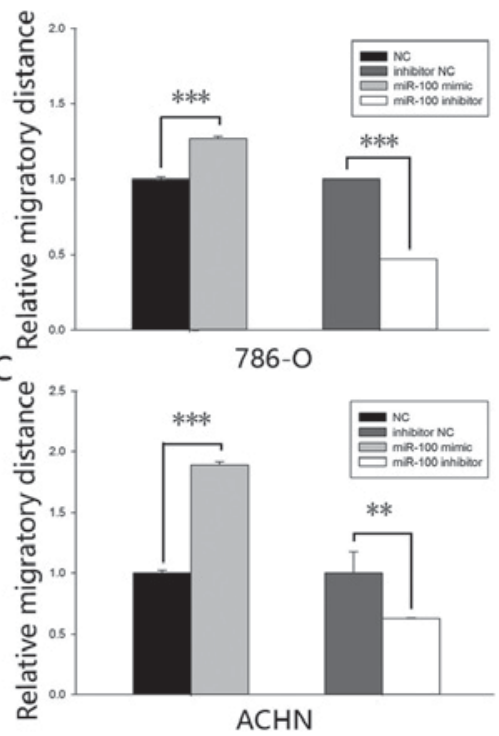

Figure 4. Wound healing assay of ACHN and 786-O cells. (A) Images captured of cell migration. Cell migratory distances of (B) 786-O and (C) ACHN cells after transfection with miR-100-5p mimic or NC and miR-100-5p inhibitor or inhibitor NC. ${ }^{*} \mathrm{P}<0.05,{ }^{* *} \mathrm{P}<0.01,{ }^{* * *} \mathrm{P}<0.001$. miR, microRNA; NC, negative control.

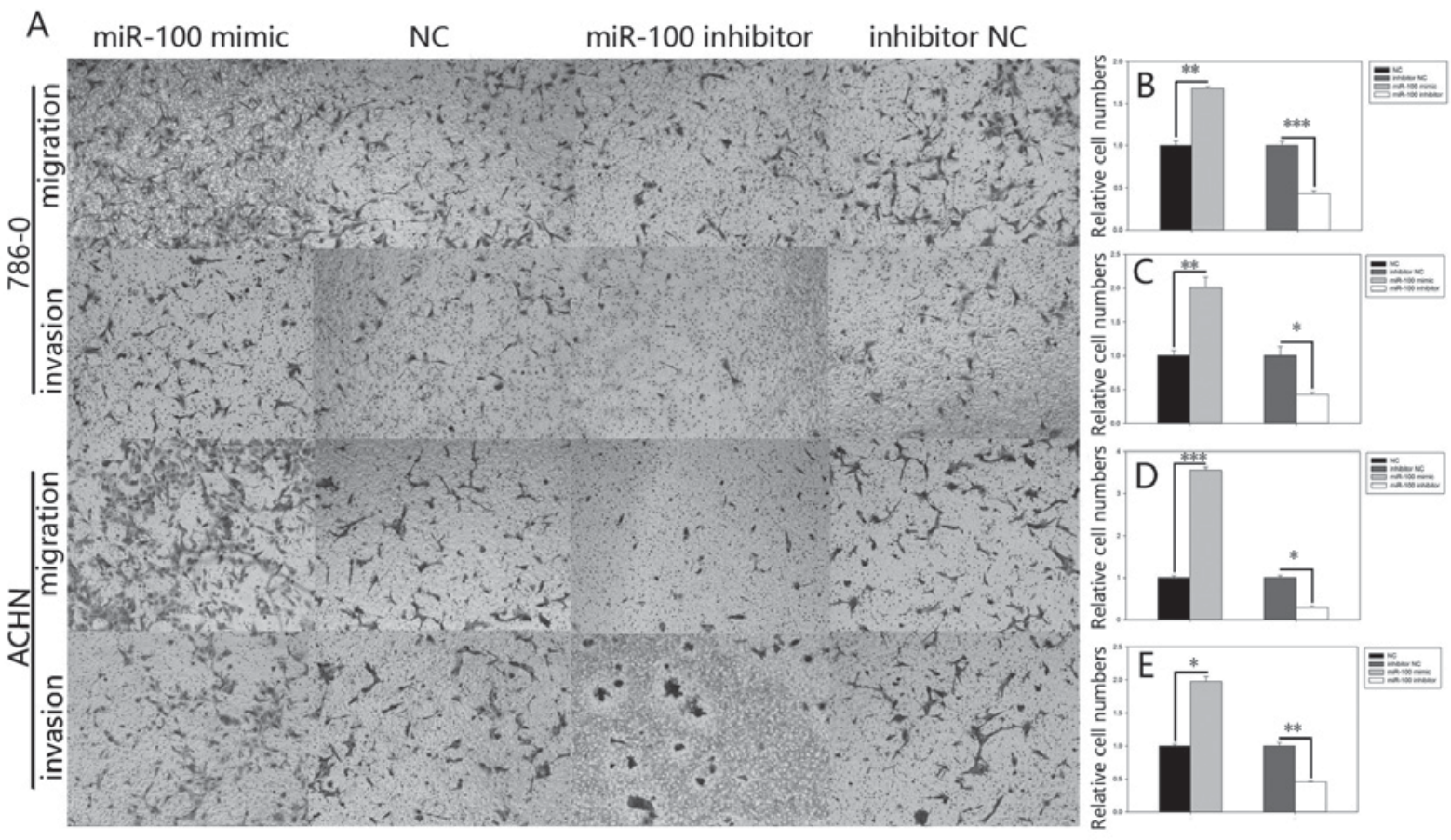

Figure 5. miR-100-5p promoted cell migration and invasion. (A) Images captured of invasion and migration. (B and C) miR-100-5p promoted migration and invasion abilities of 786-O cells. (D and E) Similar results can be observed in ACHN cells. " $\mathrm{P}<0.05,{ }^{* *} \mathrm{P}<0.01,{ }^{* * * * *} \mathrm{P}<0.001$. miR, microRNA; NC, negative control.

A series of tumors are associated with miRNAs, which are encoded by genes on fragile genomic sites or genomic regions about multiple cancer types (26). An increasing number of studies have shown that at least $20-30 \%$ of all genes are regulated by miRNAs, which are important in oncogenesis and promoting of tumors (27). Previous studies demonstrated that miR-100-5p have acted as tumor suppressor genes in different types tumor, including esophageal squamous cancer (21), glioblastoma (22), breast cancer (23) and gastric cancer (24). However, miR-100-5p was observed as an oncogene in RCC tissues compared with paired normal tissues, which suggested that there is a difference between RCC and other tumors about the underlying mechanism of miR-100-5p.

A previous study has reported that overexpression of miR-100-5p strongly associates with advanced tumor progression and unfavorable clinical outcome of patients 
A
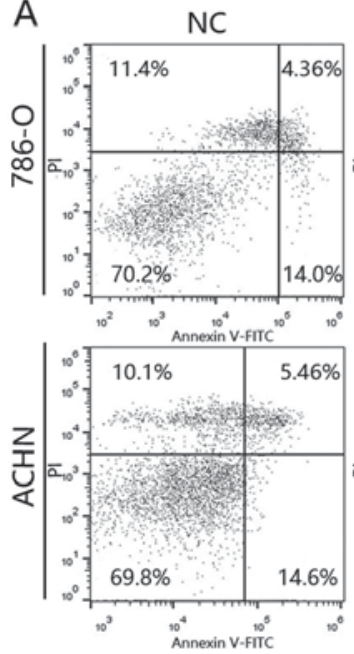
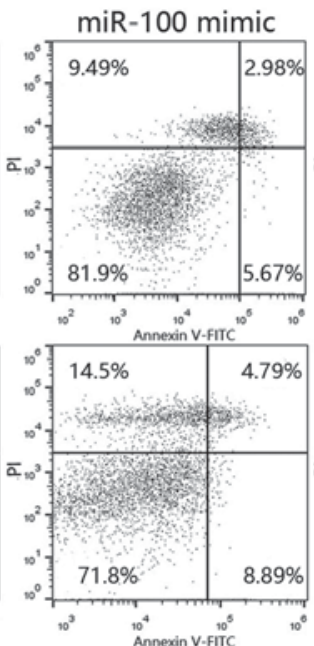
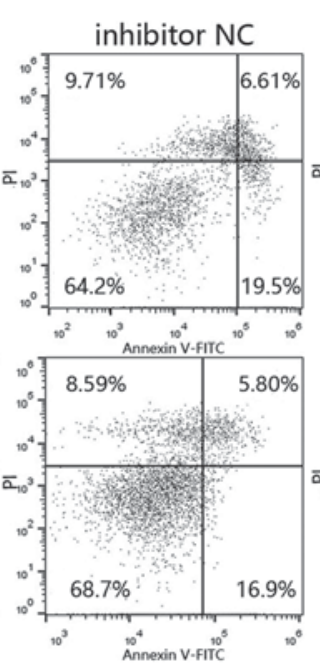
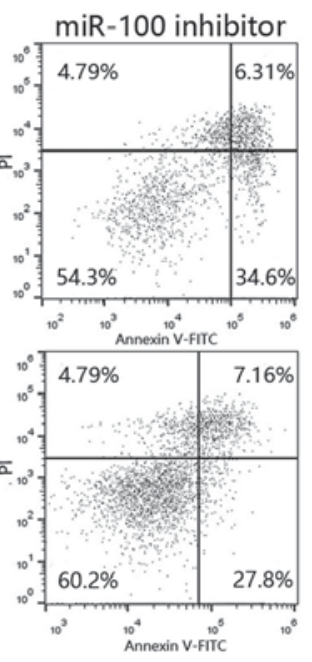
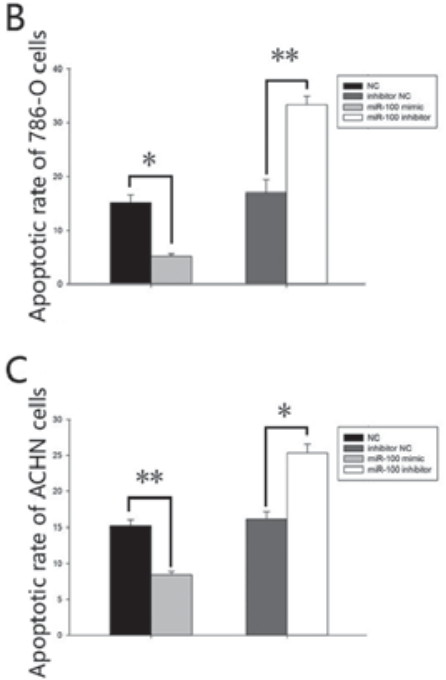

Figure 6. (A) Flow cytometry results of ACHN and 786-O cells. Cell apoptosis rate (\%) of (B) 786-O and (C) ACHN cells transfected with miR-100-5p mimic or NC and inhibitor or inhibitor NC. ${ }^{*} \mathrm{P}<0.05,{ }^{* *} \mathrm{P}<0.01,{ }^{* * *} \mathrm{P}<0.001$. miR, microRNA; NC, negative control.

with RCC (28), however, the function of miR-100-5p in RCC remains to be elucidated. Therefore, the present study aimed to explore the roles of miR-100-5p in RCC. To estimate the relative expression of miR-100-5p in 22 paired $R C C$ and adjacent normal tissues, RT-qPCR was performed in the present study. In addition, the effects of miR-100-5p mimics and inhibitor on RCC cell lines were evaluated in vitro. The results of the expression levels revealed that miR-100-5p was upregulated in RCC tissues compared with those in the paired normal tissues through qPCR. Furthermore, the present study aimed to explored whether miR-100-5p could affect RCC cell viability, migration or apoptosis, as explored by CCK8, MTT, wound healing, transwell and flow cytometric assays. It was demonstrated that $\mathrm{ACHN}$ and 786-O cells with transfection of miR-100-5p mimics were promoted the ability of cellular viability, migration and invasion but inhibited apoptosis. Conversely, ACHN and 786-O cells with transfection of miR-100-5p inhibitor were promoted the ability of apoptosis but inhibited cellular viability, migration and invasion. The results further confirmed the tumor oncogenic role of miR-100-5p in RCC.

The mechanisms about miR-100-5p affecting cell progression was complicated, and have been reported in different types of cancer. In esophageal squamous cancer, overexpression of miR-100 inhibited cell viability, migration, invasion and tumor growth through regulating target gene CXCR7 (21). In addition, miR-100-5p was also reported to be markedly downregulated in glioblastoma and could affect cell processes through regulation of FGFR3 (22). Jiang et al also found that miR-100-5p was downregulated in human breast cancer and suppressed the migration and invasion of breast cancer cells through targeting FZD-8 (23). In another previous study about human breast cancer, it revealed that MTMR3 might be a target gene of miR-100-5p and the apoptotic pathway mediated by miR-100-5p was different in various breast cancer cells (29). Furthermore, in gastric cancer, it was also reported that overexpression of miR-100-5p suppressed tumor metastasis and growth by targeting
ZBTB7A (24). In those types of cancer, restoring the level of miR-100-5p induced cell apoptosis but inhibited cell viability, migration or invasion.

Previous studies have also demonstrated that miR-100-5p could be used as a novel biomarker for diagnosis and estimation of prognosis. Epithelial ovarian cancer patients with downregulated miR-100-5p expression have shorter overall survival (30). For bladder cancer patients, low expression levels of miR-100-5p was associated with advanced clinical features and poor prognosis (31). In addition, Chen et al reported that downregulation of miR-100-5p was associated with advanced clinical features and poor prognosis of colorectal cancer patients (32). There is also a research indicating that downregulation of miR-100-5p was correlated with progressive pathological feature and poor prognosis in hepatocellular carcinoma patients (33). Therefore, it is suggested that miR-100-5p is involved in cellular processes of RCC.

Although the genetic mechanism of miR-100-5p in RCC requires further elucidation, understanding of the cellular function of miRNAs is providing novel insights into RCC (34). The present study suggested that miR-100-5p acts as an oncogene in RCC. Thus, miR-100-5p has the potential to be a biomarker for RCC diagnosis at early stages or as a molecular targeted therapy.

In conclusion, the results of the present study revealed that miR-100-5p was upregulated in RCC tissues compared with that in normal adjacent tissues. miR-100-5p was involved in cellular viability, migration, invasion and apoptosis in ACHN and 786-O RCC cell lines. Furthermore, these results suggested that miR-100-5p may function as a tumor tumorigenesis in $\mathrm{RCC}$ and may be used as a therapeutic target for renal cancer treatment in the future.

\section{Acknowledgements}

The present study was supported by the National Natural Science Foundation of China (no. 81101922), Science and Technology Development Fund Project of Shenzhen 
(nos. JCYJ20130402114702124 and JCYJ20170307111334308) the fund of 'San-Ming' Project of Medicine in Shenzhen and the fund of Guangdong Key medical subject.

\section{References}

1. Siegel RL, Miller KD and Jemal A: Cancer statistics, 2016. CA Cancer J Clin 66: 7-30, 2016.

2. Ridge CA, Pua BB and Madoff DC: Epidemiology and staging of renal cell carcinoma. Semin Intervent Radiol 31: 3-8, 2014.

3. Ferlay J, Shin HR, Bray F, Forman D, Mathers C and Parkin DM: Estimates of worldwide burden of cancer in 2008: GLOBOCAN 2008. Int J Cancer 127: 2893-2917, 2010.

4. Yan Y, Yang FQ, Zhang HM, Che J and Zheng JH: Up-regulation of flotillin-2 is associated with renal cell carcinoma progression. Tumour Biol 35: 10479-10486, 2014.

5. Patel C, Ahmed A and Ellsworth P: Renal cell carcinoma: A reappraisal. Urol Nurs 32: 182-190; quiz 191, 2012.

6. Siegel R, Naishadham D and Jemal A: Cancer statistics, 2013. CA Cancer J Clin 63: 11-30, 2013.

7. Escudier B, Porta C, Schmidinger M, Rioux-Leclercq N, Bex A, Khoo V, Gruenvald V and Horwich A; ESMO Guidelines Committee: Renal cell carcinoma: ESMO Clinical Practice Guidelines for diagnosis, treatment and follow-up. Ann Oncol 27 (suppl 5): v58-v68, 2016.

8. Rendon RA, Kapoor A, Breau R, Leveridge M, Feifer A, Black PC and So A: Surgical management of renal cell carcinoma: Canadian Kidney Cancer Forum Consensus. Can Urol Assoc J 8: E398-E412, 2014.

9. Motzer RJ, Bander NH and Nanus DM: Renal-cell carcinoma. N Engl J Med 335: 865-875, 1996.

10. Yim NH, Jung YP, Kim A, Kim T and Ma JY: Induction of apoptotic cell death by betulin in multidrug-resistant human renal carcinoma cells. Oncol Rep 34: 1058-1064, 2015.

11. Cohen HT and McGovern FJ: Renal-cell carcinoma. N Engl J Med 353: 2477-2490, 2005.

12. Hong MH, Kim HS, Kim C, Ahn JR, Chon HJ, Shin SJ, Ahn JB, Chung HC and Rha SY: Treatment outcomes of sunitinib treatment in advanced renal cell carcinoma patients: A single cancer center experience in Korea. Cancer Res Treat 41: 67-72, 2009.

13. Carthew RW and Sontheimer EJ: Origins and Mechanisms of miRNAs and siRNAs. Cell 136: 642-655, 2009.

14. Huntzinger E and Izaurralde E: Gene silencing by microRNAs: Contributions of translational repression and mRNA decay. Nat Rev Genet 12: 99-110, 2011.

15. Bartel DP: MicroRNAs: Target recognition and regulatory functions. Cell 136: 215-233, 2009.

16. Krol J, Loedige I and Filipowicz W: The widespread regulation of microRNA biogenesis, function and decay. Nat Rev Genet 11: 597-610, 2010.

17. Komabayashi Y, Kishibe K, Nagato T, Ueda S, Takahara M and Harabuchi Y: Downregulation of miR-15a due to LMP1 promotes cell proliferation and predicts poor prognosis in nasal NK/T-cell lymphoma. Am J Hematol 89: 25-33, 2014.

18. Garzon R, Calin GA and Croce CM: MicroRNAs in Cancer Annu Rev Med 60: 167-179, 2009.

19. Shenouda SK and Alahari SK: MicroRNA function in cancer: Oncogene or a tumor suppressor? Cancer Metastasis Rev 28: 369-378, 2009.
20. Guil S and Esteller M: DNA methylomes, histone codes and miRNAs: Tying it all together. Int J Biochem Cell Biol 41: 87-95, 2009.

21. Zhou SM, Zhang F, Chen XB, Jun CM, Jing X, Wei DX, Xia Y, Zhou YB, Xiao XQ, Jia RQ, et al: miR-100 suppresses the proliferation and tumor growth of esophageal squamous cancer cells via targeting CXCR7. Oncol Rep 35: 3453-3459, 2016.

22. Luan Y, Zhang S, Zuo L and Zhou L: Overexpression of miR-100 inhibits cell proliferation, migration and chemosensitivity in human glioblastoma through FGFR3. OncoTargets Ther 8: 3391-3400, 2015.

23. Jiang Q, He M, Guan S, Ma M, Wu H, Yu Z, Jiang L, Wang Y, Zong $X$, Jin $F$ and Wei M: MicroRNA-100 suppresses the migration and invasion of breast cancer cells by targeting FZD-8 and inhibiting Wnt/ $\beta$-catenin signaling pathway. Tumour Biol 37: 5001-5011, 2016.

24. Shi DB, Wang YW, Xing AY, Gao JW, Zhang H, Guo XY and Gao P: C/EBP $\alpha$-induced miR-100 expression suppresses tumor metastasis and growth by targeting ZBTB7A in gastric cancer. Cancer Lett 369: 376-385, 2015.

25. Livak KJ and Schmittgen TD: Analysis of relative gene expression data using real-time quantitative PCR and the 2(-Delta Delta C(T)) Method. Methods 25: 402-408, 2001.

26. Bhattacharya R, Nicoloso M, Arvizo R, Wang E, Cortez A, Rossi S, Calin GA and Mukherjee P: MiR-15a and MiR-16 control Bmi-1 expression in ovarian cancer. Cancer Res 69: 9090-9095, 2009.

27. Ofir M, Hacohen D and Ginsberg D: MiR-15 and miR-16 are direct transcriptional targets of E2F1 that limit E2F-induced proliferation by targeting cyclin E. Mol Cancer Res 9: 440-447, 2011.

28. Wang G, Chen L, Meng J, Chen M, Zhuang L and Zhang L: Overexpression of microRNA-100 predicts an unfavorable prognosis in renal cell carcinoma. Int Urol Nephrol 45: 373-379, 2013.

29. Gong Y, He T, Yang L, Yang G, Chen Y and Zhang X: The role of miR-100 in regulating apoptosis of breast cancer cells. Sci Rep 5: 11650, 2015.

30. Azizmohammadi S, Azizmohammadi S, Safari A, Kosari N, Kaghazian M, Yahaghi E and Seifoleslami M: The role and expression of miR-100 and miR-203 profile as prognostic markers in epithelial ovarian cancer. Am J Transl Res 8: 2403-2410, 2016.

31. Cao YH, Zhang HH, Xu HF, Duan YJ, Li Q and Huang B: Prognostic role of microRNA-100 in patients with bladder cancer. Genet Mol Res 14: 15948-15954, 2015.

32. Chen P, Xi Q, Wang Q and Wei P: Downregulation of microRNA-100 correlates with tumor progression and poor prognosis in colorectal cancer. Med Oncol 31: 235, 2014.

33. Chen P, Zhao X and Ma L: Downregulation of microRNA-100 correlates with tumor progression and poor prognosis in hepatocellular carcinoma. Mol Cell Biochem 383: 49-58, 2013.

34. Zhang B, Pan X, Cobb GP, Anderson TA: microRNAs as oncogenes and tumor suppressors. Dev Biol 302: 1-12, 2007. 